This item was submitted to Loughborough's Research Repository by the author.

Items in Figshare are protected by copyright, with all rights reserved, unless otherwise indicated.

\title{
Evaluation of overall and local ventilation in diapers
}

PLEASE CITE THE PUBLISHED VERSION

http://dx.doi.org/10.1177/0040517510369402

\section{PUBLISHER}

Sage Publications (@ The Authors)

VERSION

AM (Accepted Manuscript)

LICENCE

CC BY-NC-ND 4.0

REPOSITORY RECORD

Satsumoto, Yayoi, and George Havenith. 2019. "Evaluation of Overall and Local Ventilation in Diapers". figshare. https://hdl.handle.net/2134/6721. 
This item was submitted to Loughborough's Institutional Repository (https://dspace.lboro.ac.uk/) by the author and is made available under the following Creative Commons Licence conditions.

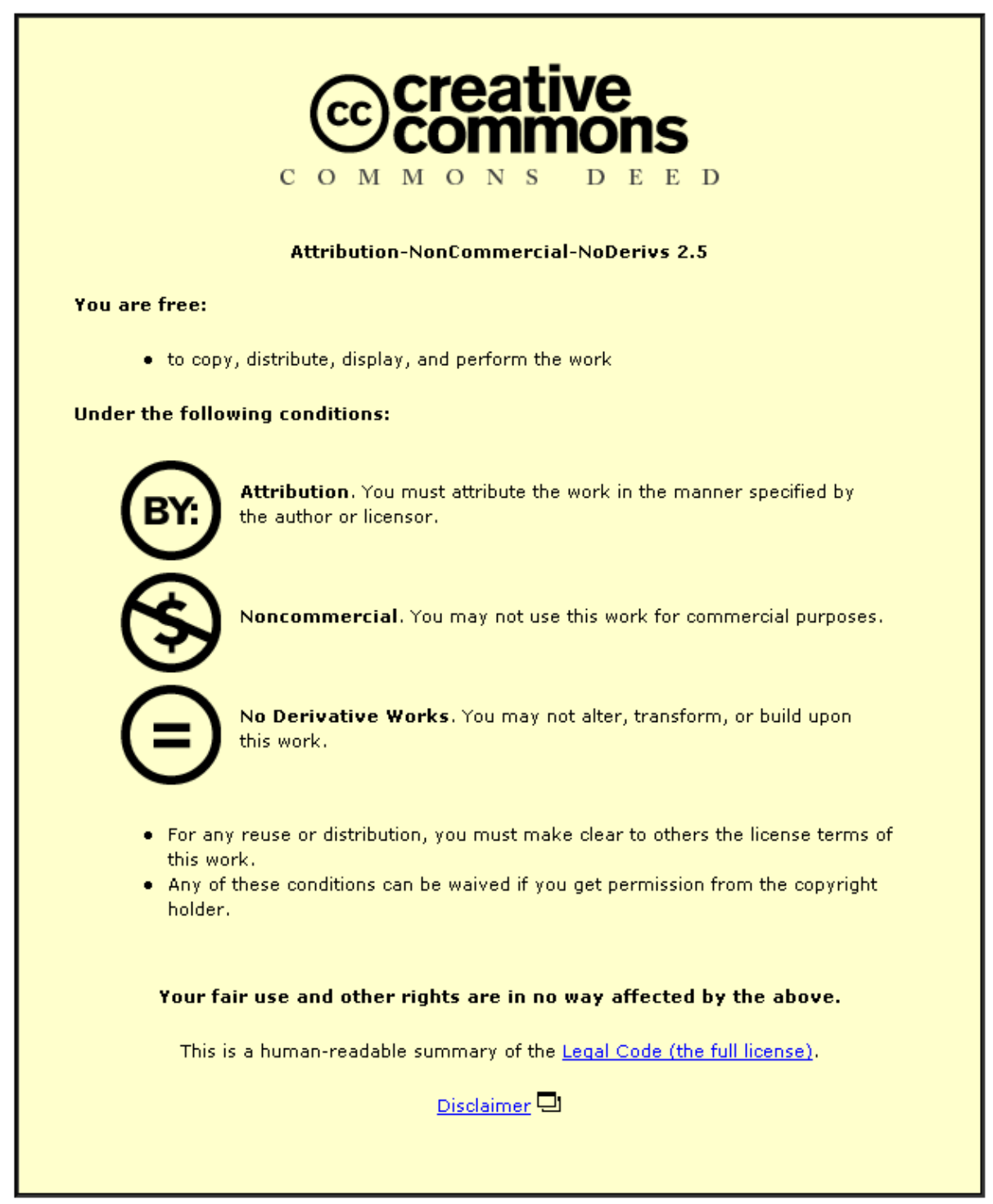

For the full text of this licence, please go to: http://creativecommons.org/licenses/by-nc-nd/2.5/ 


\section{Evaluation of overall and local ventilation in diapers}

\section{Yayoi Satsumoto') and George Havenith ${ }^{2)}$}

1) Faculty of Education and Human Sciences, Yokohama National University, Japan

2) Department of Ergonomics (Human Sciences), Loughborough University, United Kingdom

Corespond to Yayoi Satsumoto

Affiliation: Faculty of Education and Human Sciences, Yokohama National University, Japan

E-mail: satumoto@ynu.ac.jp 


\section{Evaluation of overall and local ventilation in diapers}

\section{Abstract}

A device to evaluate the distribution of the ventilation in diapers by using a tracer gas method (steady state method) was developed to investigate the effect of the design- and material-factor of diapers on heat and water vapor transfer by ventilation. This device can also measure the local quantitative evaluation of microclimate ventilation during rest or walking between the interior of the diaper and the ambient atmosphere. Using forced ventilation, it was shown that the devices' measurement captured the actual ventilation in the diapers. For the overall ventilation values it was found that the air permeability of the diaper fabric affected the ventilation but did not dominate it. It means the ventilation was affected not only by the air permeability but also by the construction and design of clothing. Leg movement caused about $20 \%$ increase of ventilation compared to the static condition. The ventilations of the pants design diapers were less affected by the movement. For the local ventilation values, the ventilation of the front upper site contributed heavily to the overall ventilation. The repeatability of the microclimate ventilation values measured by the steady state method obtained in our present study was better than that of the transient method reported in our earlier paper. It was demonstrated that the device allowed the evaluation of diaper design for the purpose of improving the microclimate in the diaper.

Keywords: thermal comfort, diaper, microclimate ventilation rate, tracer gas method, local ventilation 


\section{Introduction}

In 1981 the first domestic diapers were produced in Japan. With the development of super absorbent polymers (SAP), used in diapers since 1983, urine can be held in larger amounts and for longer, increasing the popularity and use because of its convenience. In the 1990's, as pant type disposal diapers were developed, older infants also began to use these. In the 2000's, though the birth population decreases (Japan Statistical yearbook, 2008), the production of diapers for infants still increases (Japan Hygiene Products Industry Association, 2008).

In Japan, in 2008, $22.1 \%$ of the population was over 65 years old. The aging of Japan outweighs all other nations with the highest proportion of elderly citizens. The consumption of adult diapers has already caught up with that of infant diapers. Both adult and infant markets are important and hence there is a continuous effort to improve comfort for diaper wearers. Apart from the comfort in relation to a reduced wettedness sensation, also overall thermal comfort under the diapers was identified as a relevant factor in user satisfaction. Understanding and improving this is important to maintain quality of life in old age and of infants.

Air circulation underneath a diaper is very low, especially with the wearer at rest, because the waist and groin part of a diaper is usually tightly closed and the outer surface of the diaper is typically made of impervious film laminate to hold urine without leakage. Breathable microporous film has been introduced to improve the thermal comfort of the microclimate of the diaper while keeping it waterproof. By using microporous film as outer material, the heat and moisture transfer through the diaper was improved. However it was not enough to provide comfort in a hot environment or after urine release, as shown in subject trials (Tezuka, 2007).

As air exchange through openings of waist and groin parts during walking (bellows action) can reduce humidity and hydration in the diaper, air exchange by this bellows effect is important for 
the heat and mass transfer from the human body when the wearer feels humid in a hot environment or during activity. However it is yet unclear how much ventilation actually occurs and how it can reduce the humidity in a diaper.

Crockford et al. (1972) developed a way to measure the air exchange in protective clothing directly using a tracer gas method (Nitrogen washout method). As their transient tracer gas method needed the clothing microclimate volume measurement as well to calculate ventilation rate, Birnbaum and Crockford (1978) proposed a vacuum method to measure the garment microclimate volume. This tracer gas method has been applied to many clothing types, including diapers (Berglund et al., 1997) and infant bedding (Holland et al., 1999).

Havenith et al. (1990a), showed the effect of walking and/or wind on the reduction of thermal insulation and proposed a correction equation to calculate the resultant dynamic thermal insulation from the static thermal insulation revised by walking speed and/or wind speed. Subsequently, Havenith et al. (1990b) also proposed a way to calculate the vapor resistance from the measured ventilation rate, and studied changes in ventilation due to wind and motion using a tracer gas method (steady state method, Lotens and Havenith, 1988). They further compared the different tracer gas methods (Havenith \& Zhang, 2000; Havenith et al., 2010). Ueda \& Havenith $(2005,2006)$ investigated the effect of air permeability, opening condition and clothing air gap between skin and clothing on ventilation during walking and/or wind in protective clothing. They found that the ventilation was affected not only by the air permeability (one of the material factors of clothing) but also by design features like openings and the air gap size between skin and clothing.

Satsumoto et al. $(2000,2003,2005)$ investigated the bellows action mechanism on heat transfer by using a simple model to simulate bellows action. They found that the narrower the air gap 
between skin and clothing, the larger the ventilation that occurs near openings because of bellows action.

Ghaddar et al. $(2002,2005,2008)$ also investigated the ventilation mechanism analytically by using the periodical motion model of the arm part of the body. It was found that the ventilation was affected by opening condition, frequency, and amplitude of arm movement. Though the results were accurate, they are limited for the arm part only.

Satsumoto et al. (2008) developed a device to evaluate the ventilation of diapers by using a tracer gas dilution method (transient method). It was found that the ventilation was affected not only by the air permeability (one of the material factors of clothing) but also by design and constructive factors like openings and the air gap between skin and clothing. However in this testing the repetition error was rather large because the microclimate size changes each time with dressing. To improve the repetition error, a three dimensional mesh layer was put on under the diaper, which had the role to make the constructive factor (i.e. the air gap between skin and diaper) more consistent for any repetition. However, this also changed the air circulation. As an alternative, a vacuum pump was used whose inlet and outlet were inserted into the diaper to accelerate the circulation and mixing underneath the diaper. Though the forced current due to the vacuum pump caused the repetition error to decrease this was different from the real air circulation situation in a diaper.

In the present study, the diaper evaluation device was developed further in that it was modified to use the steady state tracer gas method (Havenith et al., 2000, 2010) and to allow localized microclimate ventilation measurements in different locations in the diaper. Using this new setup, a study was designed to determine the effect of the design- and material- factors of diapers on microclimate air exchange due to ventilation between the interior of the diaper and the ambient 5 
atmosphere. This was studied quantitatively during rest or walking. The results will be compared to the experimental results obtained with the former developed device. The goal is to create a device for the evaluation of diaper design for improved thermal comfort.

\section{Methods}

\section{Garments}

To study the effect of permeability on ventilation, two pants were chosen, one highly air permeable, the other air impermeable. Three conventional disposable pant design diapers for 12 to 24 month old infant ( $L$ size) were also used for the experiments. All three are commercially available, slim type, diapers. The photographs of two pants and a schematic diagram of diapers are shown in Fig.1. The two pants are made of polyester fabric. For the impermeable pant, this is laminated with an impermeable polyurethane coating. The three commercial diapers consist of three parts: a part which contains super absorbent polymer (SAP), pulp and absorbent paper inside unwoven cloth, a part with one layer of a non-woven fabric (SIDE1), and a part with two layers of non-woven fabric (SIDE2). The surface cover area of each part is shown in Table 1 and Fig.2. Among the commercial diapers, the covered area of diaper $Z$ is smaller than of the other two diapers. The weight, thickness and the air resistance, area-weighted among SAP, SIDE1 and SIDE2 measured by KES method, and water vapor permeability of the unwoven part of diaper measured by the JIS L1099 A-2 Method, are also shown in Table 1. Among diapers, the weight of diaper $Z$ is lighter than diaper $X, Y$ but thickness of $Z$ is thicker than others. The air permeability of diaper $\mathrm{X}$ is larger than diaper $\mathrm{Y}, \mathrm{Z}$. The water vapor permeability of diapers is similar. 


\section{Walking infant manikin}

To estimate the effect of walking/crawling on the ventilation of the diaper, a walking infant (of about 12 to 24 months old) manikin of the body around the buttock and upper leg part has been developed by Unicharm Corporation as shown in Fig.3. The manikin skin is made of flexible polyurethane material. Walking speed was decided by an average value measured by monitoring walking infants of one to two years old. The walking pace of manikin is $34 \mathrm{~cm} / \mathrm{step}$. The walking speed can be changed from 0 to $48 \mathrm{steps} / \mathrm{m}(1.6 \mathrm{~km} / \mathrm{h})$. In this study, the maximum speed 1.6 ] was chosen to study the effect of leg movement.

\section{Tracer gas methods}

A steady state tracer gas method was used for measuring air exchange in clothing (Havenith et al., 2000, 2010). In the case of the previously used transient method, a measurement to estimate the air volume under the diaper is needed (Berglund, 1997) to calculate the air ventilation rate. As it is hard to measure air volume during the tracer gas experiment, which is also expensive and time consuming (Havenith \& Zhang, 2000, 2010), we chose the steady state method to reduce the repetition error caused by variations in air volume. The steady state method does not need the air volume under the diaper to calculate the microclimate ventilation rate. As demonstrated by Havenith et al. (2010) this method provides excellent repeatability, accuracy and sensitivity.

\section{Steady state tracer gas system}

Figure 2 shows the schematic diagram of the ventilation system. The tracer gas $\left(100 \% \mathrm{CO}_{2}\right)$ was mixed with room air to a concentration around $5000 \mathrm{ppm}(0.5 \%)$ and a precisely controlled 
flow (mass flowmeter model 41221 , TSI CO., LTD, accuracy $2 \%$ of reading) was introduced in the diaper via a gas distribution tubing system. The concentration in the inlet tubes was determined by a $\mathrm{CO}_{2}$ analyzer (GMP343, Vaisala CO., LTD; accuracy $\pm(5 \mathrm{ppm}+2 \%$ of reading)). Microclimate air samples were taken with an identical tubing system (outlet), and outlet concentration was determined by the same, fore mentioned, gas analyzer (switching, using 3 way valves, between inlet and outlet with the same analyzer avoids influence of sensor differences). The inlet and the outlet tube were branched to 8 distribution / sampling tubes respectively to make the $\mathrm{CO}_{2}$ distribution underneath the diaper uniform and to provide a uniform sample of the whole microclimate. To further improve sampling uniformity, six holes were drilled at $1 \mathrm{~cm}$ pitch from the end of each tube.

The inlet flow rate $\left(\mathrm{V}_{\text {in }}\right)$ and outlet flow rate $\left(\mathrm{V}_{\text {out }}\right)$ must be controlled to precisely the same value $(0.5 \mathrm{l} / \mathrm{min})$ in case of the steady state tracer gas method to avoid introducing forced ventilation. The pump and the flow controllers were used to manage these steady state flows.

$\mathrm{V}=\mathrm{V}_{\text {in }}=\mathrm{V}_{\text {out }}$

The box in which the manikin was placed (net size was $530 \times 680 \times 400 \mathrm{~mm}$, made of PMMA plate of $10 \mathrm{~mm}$ thickness) was ventilated before and after each experiment. The front and back panel of the box were open, avoiding $\mathrm{CO}_{2}$ build up in the box during the test. The background concentration in the box was also monitored by the $\mathrm{CO}_{2}$ analyzer. The waist part of the manikin was fixed to the top of the box.

\section{Measurement procedure}

The experiment was carried out in an air conditioned chamber at $20 \pm 2.0{ }^{\circ} \mathrm{C}, 50 \pm 10 \%$ relative humidity, air flow $<0.2 \mathrm{~m} / \mathrm{s}$. After the tracer gas circulation pumps were switched on, the inlet 
$\mathrm{CO}_{2}$ concentration was adjusted to about 5000ppm. Then the flow rate of inlet and outlet were equalized and monitored. Then by switching 3 way valves, the $\mathrm{CO}_{2}$ concentration of inlet and outlet were monitored and recorded until all concentrations reached a steady state. The $\mathrm{CO}_{2}$ concentration of the box environment was monitored and recorded before and after experiments and the average used in the calculations (on average $\mathrm{CO}_{2}$ concentration dropped by $11 \mathrm{ppm}$ over the tests, showing that the open front and back were effective in preventing $\mathrm{CO}_{2}$ build up in the box; the average absolute difference pre to post was $26 \mathrm{ppm}$ ).

Three specimens were tested for each of five design samples (two pants and three commercial diapers). For each specimen experiments were repeated four times for overall evaluation and three times for local evaluation of each site. In case of walking slow, experiments were done only for one specimen. After each experiment, to remove any $\mathrm{CO}_{2}$ from the box, the vacuum fan and three fans equipped in the box were used.

\section{Method of Analysis}

For the steady state method, steady state data of $\mathrm{CO}_{2}$ concentration of inlet $\left(\mathrm{CO}_{2} \mathrm{in}\right)$, outlet $\left(\mathrm{CO}_{2} \mathrm{Out}\right)$, and the atmosphere in the box $\left(\mathrm{CO}_{2} \mathrm{e}\right)$ and flow rate $(\mathrm{V})$ in and out of the diaper are needed to calculate the microclimate ventilation rate (VENT) shown in equation (2) (Lotens and Havenith, 1988).

$\mathrm{VENT}=\mathrm{V} \times \frac{\mathrm{CO}_{2} \text { in }-\mathrm{CO}_{2} \text { out }}{\mathrm{CO}_{2} \text { out }-\mathrm{CO}_{2} \mathrm{e}}$

Where, $\mathrm{CO}_{2}$ in : the $\mathrm{CO}_{2}$ concentration of the inlet (ppm), $\mathrm{CO}_{2}$ out: the $\mathrm{CO}_{2}$ concentration of the outlet (ppm), $\mathrm{CO}_{2} \mathrm{e}$ : the $\mathrm{CO}_{2}$ concentration of the atmosphere in the box (ppm), V: flow rate both inlet and outlet (1/min.). 


\section{Validity of steady state method}

Extensive validity testing of the steady state method was performed by Havenith et al. (2010). As an additional check, the validity of the current apparatus using the same method was tested by measuring the ventilation caused by a forced convection flow that was introduced into the diapers. The forced flows ranged from 0 to $1.0 \mathrm{I} \cdot \mathrm{min}^{-1}$.

\section{Local evaluation by steady state method}

To apply the steady state tracer gas method for the measurement of local ventilation within different areas of the diapers, extra sample tubes were set on the skin of the manikin at four sites: the front groin part (L1), the front upper site covered with non woven fabric (L2), the back middle site covered with absorbent (L3), the back upper site covered with non woven fabric (L4) as shown in Fig.5. These local sampling tubes were connected to a separate vacuum pump, and activated one at a time. As this additional sampling flow would increase the total Vout and create an imbalance between Vin and Vout (eq. 1), the main sampling flow needs to be adjusted to reinstate equality between Vin and Vout. In this case equation (3) must be used instead of equation (1):

$$
\mathrm{V}_{\text {in }}=\mathrm{V}_{\text {out-main }}+\mathrm{V}_{\mathrm{l}}
$$

Where $\mathrm{V}_{\text {out-main: }}$ flow rate of main tube. $\mathrm{V}_{\mathrm{I}}$ :flow rate of the local flow.

Assuming the main flow is divided into $n$ sampling branches and a single local sampling tube is added, and attempting to keep the flow from all sampling tubes equal, the flow rate $V_{1}$ is shown in equation (4) as the equation (3) must be kept.

$\mathrm{V}_{\mathrm{l}}=\frac{\mathrm{V}_{\text {in }}}{\mathrm{n}+1}$

So $V_{\text {out-main }}$ is shown in equation (5). 
$\mathrm{V}_{\text {out-main }}=\mathrm{n} \times \mathrm{V}_{\mathrm{l}}$

\section{Method of Analysis of local evaluation}

For the local evaluation, we can calculate the local microclimate ventilation rate of each local site $\left(\mathrm{VENT}_{\mathrm{l}}\right)$, shown in equation (6)

$\mathrm{VENT}_{1}=\mathrm{V}_{\mathrm{l}} \times \frac{\mathrm{CO}_{2} \text { in }-\mathrm{CO}_{2} \text { local }}{\mathrm{CO}_{2} \text { local }-\mathrm{CO}_{2} \mathrm{e}}$

Where: VENT : local microclimate ventilation rate $(\mathrm{l} / \mathrm{min}), \mathrm{V}_{1}$ : flow rate of each local site $(\mathrm{l} / \mathrm{min})$, $\mathrm{CO}_{2}$ local: $\mathrm{CO}_{2}$ concentration of each local site I (ppm), $\mathrm{CO}_{2} \mathrm{e}: \mathrm{CO}_{2}$ concentration of environment.

\section{Methods of Statistical analysis}

The experimental results of VENT underwent a factorial analysis of variance (ANOVA), by using SPSS ver.15. For the overall experimental results, a two way ANOVA was used to identify significant effects of: 1 : the type of diaper and 2: the effect of motion. For the local experimental results, a three way ANOVA was used to identify significant effects of the factors: 1: location, 2: type of diaper and 3: motion. Post-hoc test on each of above ANOVA's were conducted to examine the multiple comparison of individual mean differences by using the Scheffe method in case that equal variances were assumed and by using the Tamhane method in case that equal variances were not assumed.

\section{Results and Discussion}

\section{Validity of steady state method}

The results of the measurement of a forced ventilation flow for the current setup are presented in

Fig. 6. Results indicate that a linear relation is observed between the forced ventilation and the 11 
measured ventilation. The intercept of the regression line however does not pass through 0,0 but at zero forced ventilation still a ventilation of $0.4 \mathrm{I} \cdot \mathrm{min}^{-1}$ is measured. This value is comparable to natural ventilation in standing still, no wind conditions, and is consistent with observations by Havenith et al. (2010) for forced ventilation tests.

\section{Total diaper ventilation}

In the measurement of overall ventilation (fig. 7) a significant main effect of both diaper type $(p<0.001)$ and motion $(p<0.001)$ was observed. The interaction of diaper type and motion was not statistically significant however $(p=0.3)$. Motion increased ventilation on average by $20 \%$. Post hoc testing showed that the increase caused by the motion was significant for all diaper types (Table 2). Post hoc testing on the different diaper comparisons (Table 3) showed that ventilation at rest was significantly different between all diapers $(p<0.001)$ except between diaper $X$ and $Y$ and between $X$ and $Z$. VENT of the permeable pant was largest and VENT of the impermeable one was smallest. For the movement condition, again all diapers except $\mathrm{X}$ and $\mathrm{Y}$ had significantly different ventilations $(p<0.001$ for all except $X$ versus $Z: p<0.05)$. Multiple comparisons were conducted by using the Tamhane method.

The lack of differences between $X$ and $Y$ and at rest also for $X$ and $Z$ may be caused by the similarity in their air permeabilities, which are all quite close relative to the permeable and impermeable pant. $Z$ nevertheless shows a higher VENT than $X$ and $Y$ during movement, despite having the highest air resistance of the three. This may be due to the smaller surface cover area (one of the different design) used in $\mathrm{Z}$ as shown in Fig.2. 


\section{Effect of air resistance of material on VENT}

Figure 8 shows the relation between the microclimate ventilation rate and the air resistance of the diapers and pants for both rest and walking. Though there are still sizeable repetition errors as shown by the error bars (SD), it is clear that, as a general rule, the smaller the air resistance is, the larger the microclimate ventilation rate is. This means that ventilation increases as to be expected with air permeability. The slope of the regression line seems steeper for walking indicating an interaction of air permeability and walking. Variation is present in the data for diapers $\mathrm{X}, \mathrm{Y}$ and $\mathrm{Z}$ where their ventilation is not exactly ranked with air permeability changes. Based on experience with full garments (Havenith et al., 1990, 2000, Ueda et al. 2005, 2006) this is most likely caused by design differences, which given the small difference in air permeability between these diapers, becomes a more important parameter. For resting, the datapoints suggest a possible non-linear relation between ventilation and air permeability, though too few points are present to draw a conclusion on this point.

\section{Results of local microclimate ventilation rate}

The local ventilation results were analyzed using three-way ANOVA (factors: location; diaper type and motion). All three factors $(p<0.001)$ and interactions $(p<0.05)$ except interaction of diaper/motion were statistically significant. The result of the post hoc test for location is shown in Table 4 and the result for diaper type in Table 5. Over all diapers together, all locations differed significantly except $L 1$ and $L 3(p<0.001)$. Location $L 2$ had the highest ventilation, followed by $L 4$, both around the upper end of the diaper. The locations around the leg opening and in the center of the absorptive area had the lowest ventilation of similar magnitude.

For the comparison of the diaper type, despite different ventilation values, only the local ventilation of the impermeable and permeable pants differed significantly from the other diapers 13 
(for impermeable pant; $p<0.001$ against all others, for permeable pant; $p<0.01$ against diaper $X$, $\mathrm{Y}, \mathrm{p}<0.05$ against diaper $\mathrm{Y}$ ). As illustrated in Fig. 9 for location $\mathrm{L} 2$, the local ventilation of diaper $\mathrm{X}$, $\mathrm{Y}$ and $\mathrm{Z}$ showed much more variation between the repeated measurements, causing the lack of statistical power. The much lower repeatability in $\mathrm{X}, \mathrm{Y}$ and $\mathrm{Z}$ versus the two pants is probably due larger variation in fit when the normal diaper is newly applied for each repeat measurement, while the pant has a more consistent fit. This is not a problem of the method however, but real life variability.

\section{Comparison of location}

Figure 10 shows the local distribution of the microclimate ventilation rate for diaper $\mathrm{X}$ during rest and walking. The result of the post hoc test for location is shown in Table 6. As in the overall comparison, L2 is by far the highest ventilated location ( $p<0.001$ against all others) followed by L4 ( $p<0.001$ against L1 and L3). L1 and L3 are not significantly different. The VENT of L1 and L3 was small because these sites are covered with absorbent. Though both $L 2$ and $L 4$ are covered with nonwoven fabric, the lower site near L4 is also covered with absorbent material which apparently reduces the air current. The ventilation of the front upper site (L2) contributes most to the overall (main) ventilation.

\section{Effect of walking speed}

Figure 11 shows the effect of movement speed on VENT for the impermeable pant. The walking speeds chosen were normal speed for 1 to 2 years infant; $1.0 \mathrm{~km} / \mathrm{h}$ (48 step/min) and half of this; $0.5 \mathrm{~km} / \mathrm{h}$ (24 step/min). An increase of VENT was seen in relation to walking speed. For this pant, the air space is larger than the one of diapers $X, Y$ and $Z$, and it is also thinner as 
shown in Table1. The result of the post hoc test for motion is shown in Table 7. A movement effect by bellows action between rest and walking normal was seen in main $(p<0.05)$ and was seen between rest and walking slow at L1, L2 $(p<0.05)$. The difference between slow and normal is not always significant. As experiments of walking slow was done only four repetition for overall (main) and three repetition for local of one specimen, the significant differences can be seen in limited cases. We must do the further repetition about it.

\section{Comparison of two tracer gas method}

We compared the overall microclimate ventilation rate of our steady state method with the one measured by the transient method in our earlier paper (Satsumoto et al., 2008). To calculate the microclimate ventilation rate by the transient method, an estimate of the air volume under the diaper is needed (Berglund, 1997). As it was found to be difficult to measure the microclimate air volume using the original Birnbaum and Crockford method, with similar difficulties as described by Havenith and Zhang (2000), the air volume was measured in a separate experiment by three dimensional body scanning (VIVID910, KONICA MINOLTA CO., LTD; accuracy $\pm 0.10 \mathrm{~mm}$ ) as described by Havenith et al. (2010). The microclimate volume was about $300 \mathrm{~cm}^{3}$ including the diaper itself. By multiplication of the air volume (liters) and the air exchange rate $\left(\mathrm{min}^{-1}\right)$, the microclimate ventilation rate $(\mathrm{I} / \mathrm{min})$ can be calculated (Berglund, 1997). It was observed however that the repeatability of this measurement was low as the fit of the diapers changed each time with renewed donning, and this would be different at the time of the actual ventilation measurement. In an attempt to improve the repeatability and to make the $\mathrm{CO}_{2}$ concentration just after the injection uniform in the microclimate of diaper, air in the microclimate was 'stirred' by a 15 
vacuum pump. In addition, a three dimensional mesh was put on under the diaper as shown in Fig.12 to create a more repeatable air gap. Figure 13 shows the comparison VENT of the two tracer gas methods together with the Coefficient of Variation (CV; dividing the standard deviation by the average value). For the revised transient method, (transient-revised) due to the introduction air mixing and the mesh layer, ventilation was much higher, but as hoped CV was much lower. Though the repetition error decreases with this system, the observed ventilations seem unrealistically high. Such an increase in ventilation by the introduction of a mesh was described earlier by Lotens and Havenith (1998).

For the steady state method which was studied by using the newly developed device (no mesh fabric under diaper and no circulation pump), both the standard deviation and CV value decreased compared to the original transient method used in earlier studies. Hence the repeatability is improved for the steady state tracer gas methods.

\section{Conclusion}

A device to evaluate the distribution of the ventilation in diapers by using tracer gas methods (steady state method) was developed to investigate the effect of the design- and material-factor of diapers on heat and water vapor transfer by ventilation. The method was shown to be sensitive enough to show statistically significant differences in ventilation between diaper types, movement levels and different locations in the diapers. For the tested samples, the pants showing the best repeatability attributed to their consistent fit in repeated donning. Normal diapers show much higher variation in donning, reflected in the repeatability and lower significance levels. The permeability of the fabrics used affected the ventilation but did not dominate it. Ventilation was affected not only by the air permeability but also the design of the 
diapers, like size of openings of waist and legs, cover area and the air gap between skin and diapers.

Leg movement caused about $20 \%$ increase of ventilation compared to the static condition. The pants design diapers were less affected by the walking movement. For the local ventilation values, the ventilation of the front upper site contributed heavily to the overall ventilation.

The repeatability of the microclimate ventilation values measured by the steady state method obtained in our study was better than that of the transient method in our earlier paper. It was demonstrated that the device allows the evaluation of diaper design for the purpose of improving the microclimate in the diaper.

\section{Acknowledgments}

We give thanks to Unicharm Corporation for their help to this study. We thank the staff of Unicharm Corporation, Loughborough University and Yokohama National University who participated in this study.

\section{References}

1. Berglund, L.G. and Akin, F. J., "Measurement of air exchange in diapers by tracer gas methods", TAPPI J., 80(9), 173-178 (1997)

2. Birnbaum, R. and Crockford, G. W., "Measurement of the clothing ventilation index", Applied Ergonomics, 9,194-200 (1978)

3. Crockford, G.W., M. Growder, and S.P. Prestidge, S.P., "A tracer gas technique for measuring clothing microclimate air exchange rates", Brit, J. Indust. Med. 29, 378-386 
4. Diaper News 40, Japan Hygiene Products Industry Association (2002)

5. Ghaddar, N., Ghali, K., Harathani, J. and Jaroudi, E., "Ventilation rates of micro-climate air annulus of the clothing-skin system under periodic motion", Int. J. of Heat Mass Transfer, 48 (15), 3151-3166 (2005)

6. Ghaddar, N., Ghali, K. and Jreije, B., "Ventilation of Wind-Permeable Clothed Cylinder Subject to Periodic Swinging Motion: Modeling and Experimentation", ASME J. of Heat Transfer, 130 (9), 091702-1-11 (2008)

7. Ghali,K., Ghaddar, N. and Jones, B. "Empirical evaluation of convective heat and moisture transport coefficients in porous cotton medium", ASTM,124, 530-537 (2002)

8. Havenith, G., Heus, R. and Lotens, W. A., "Resultant clothing insulation, a function of body movement, posture, wind, clothing fit and ensemble thickness", Ergonomics, 33 (1)67-84 (1990a)

9. Havenith, G., Heus, R. and Lotens, W. A., "Clothing ventilation, Vapour resistance and permeability index: changes due to posture, movement and wind, Ergonomics, 33(8),989-1005 (1990b)

10. Havenith, G. and Zhang, P., "Comparison of Different Tracer Gas Dilution Methods For The Determination of Clothing Vapour Resistance", EPSRC Report on Project GR/N10509/01 (2000)

11. Havenith, G. Ping Zhang, Kent Hatcher and Hein Daanen, "Comparison of two tracer gas dilution methods for the determination of clothing ventilation and of vapour resistance", Ergonomics; accepted with changes, (2010).

12. Holland, E.J., Wilson, C.A., Laing, R.M., and Niven, B.E., "Microclimate ventilation of 18 
infant bedding", Int. J. Clothing Science and Technology, 11(4), 226-239 (1999)

13. Japan Hygiene Products Industry Association (2008)

14. Japan Statistical year book, Statistics Bureau, Director-General for Policy \& Statistical Research and Training Institute(2008)

15. Lotens W.A., Havenith, G. "Ventilation of rainwear determined by a trace gas method". In: Environmental Ergonomics. Mekjavics, Bannister, Morrison Eds., Taylor and Francis, Philadelphia, p. 162-175, 1988.

16. Satsumoto, Y., Haihua, W., Hasebe, Y., Ishikawa, K. and Takeuchi, M., "The Effect of Bellows Action on Heat Transfer in Clothing System, Part1 The Effect of Size of Air Space and Air Permeability of Clothing", Sen'l Gakkaishi, 56 (11) 524-536 (2000)

17. Satsumoto, Y., Itou, Y., Hasebe, Y. and Takeuchi, M., "The Effect of Bellows Action on Heat Transfer in Clothing System, Part2 The Effect of Opening condition of Clothing", Sen’i Gakkaishi, 59 (1) 22-29 (2003)

18. Satsumoto, Y. and Takeuchi, M. "The effect of bellows action on heat transfer in clothing system -The effect of the number and the depth of opening", Proceedings of the third international conference on human-environment system,ICHES'05, in Tokyo, Japan,12 (2005)

19. Satsumoto1, Y., Takeuchi, M., Habu, C., Yoshizaki, A., Imamura,Y., Wada, M., Akaki, K. and Miyazawa, K., "Development of Device to evaluate the ventilation of diaper", Proceedings of Korea - Japan Joint Symposium on Human - Environment System, HES32 in Cheju, Korea, November. 2008

20. Tezuka, K., graduate theses, Yokohama National University (2007)

21. Ueda, H. and Havenith, G., "The effect of fabric air permeability on clothing ventilation", 
in Y. Tochihara and T. Ohnaka, (Eds), Environmental Ergonomics, Elsevier Ltd., London, 343-346 (2005)

22. Ueda, H., Inoue, Y., Matsudaira,M. , Araki, T. and Havenith, G., "Regional microclimate humidity of clothing during light work as a result of the interaction between local sweat production and ventilation", Int. J. Clothing Science and Technology, 18 (4), 225-234 (2006)

\section{Table and FIGURE CAPTIONS}

Table 1 The characteristics of materials for the different diaper types. Air resistance as measured by the KES method, and water vapor permeability of the unwoven part of diaper measured by the JIS L1099 A-2 Method.

Table 2 Multiple comparison of mean differences between the different diaper types.

Table 3 Comparison of mean differences for the different diaper designs and significance of the walking effect.

Table 4 Comparison of the local ventilation values for the 4 studied locations. Unit: (1/min)

Table 5 Post hoc analysis of the differences in ventilation between the different diaper designs for the location $L 2$ as defined in fig. 3 . Unit: $(I / \mathrm{min})$

Table 6 Post hoc comparison of the local ventilation values for the 4 studied locations in case of diaper X. Unit:(l/min)

Table 7 Post hoc comparison among rest and two speeds of motion on local ventilation values for the 4 studied locations in case of impermeable pant. Unit:( $(1 / \mathrm{min})$

Fig.1 Photograph of two pants and schematic diagram of commercial diapers.

Fig.2 Surface cover area of three commercial diapers.

Fig.3 Photograph of the ventilation apparatus showing the manikin model and the movement mechanism inside the Perspex box. The box walls facing the front and back of the manikin are open to the environment to avoid $\mathrm{CO}_{2}$ buildup.

Fig. 4 Schematic diagram of ventilation system.

Fig.5 Local measurement sites.

Fig.6 Validation of ventilation data by comparison with forced convection values. 
Fig.7 Overall microclimate ventilation rate of diapers and pants. All comparisons except those indicated are statistically significant. ns: not significant. Per-pant=permeable pant; Imp pant=Impermeable pant diaper.

Fig.8 Relation between area weighted air resistance and the microclimate ventilation rate of diapers and pants. For the impermeable pant, as its air resistance could not be measured, an estimate was used as input.

Fig.9 Local microclimate ventilation rate of diapers and pants for location L2 in relation to diaper type and movement. Values are mean $\pm S E$. For significance levels see Table 5.

Fig.10 Local distribution of ventilation rate for diaper X. All comparisons except those indicated are statistically significant. ns: not significant. For significance levels see Table 6.

Fig.11 The effect of walking speed on local microclimate ventilation rate for the impermeable pant. Values are mean $\pm S E$. Differences between rest and walk normal are significantly different only in main. Differences between rest and walk slow are significantly different only at L1 and L2. For significance levels see Table 7.

Fig.12 Mesh fabric placed underneath the diapers to stabilize the microclimate volume.

Fig.13 Comparison of the two tracer gas methods. Left: transient method; centre: modified transient method; right: steady state method. Ventilation for rest and walking ( $\pm S E)$ and the coefficient of variation for these tests (expressed as fraction of the mean). 
Table 1 The characteristics of materials for the different diaper types. Air resistance as measured by the KES method, and water vapor permeability of the unwoven part of diaper measured by the JIS L1099 A-2 Method.

\begin{tabular}{l|l|l|l|l|l|l|l|l|l|l|l}
\hline Sample & $\begin{array}{l}\text { Weight } \\
(\mathrm{g})\end{array}$ & $\begin{array}{l}\text { Thick- } \\
\text { ness } \\
\text { AAV** } \\
(\mathrm{mm})\end{array}$ & \multicolumn{3}{|l|}{ Covered Area $\left(\mathrm{cm}^{2}\right)$} & \multicolumn{3}{l|}{ Air resistance $(\mathrm{kPa} \cdot \mathrm{s} / \mathrm{m})$} & $\begin{array}{l}\text { Water vapor } \\
\text { permeability } \\
\text { of non woven } \\
\left(\mathrm{g} / \mathrm{m}^{2} / 24 \mathrm{~h}\right)\end{array}$ \\
\hline Per pant & 11.42 & 0.24 & 756 & - & - & - & 0.02 & - & - & - & 6377.7 \\
Diaper X & 8.82 & 1.22 & 767 & 306 & 245 & 215 & 1.93 & 4.65 & 0.14 & 0.09 & 4525.6 \\
Diaper Y & 9.25 & 1.47 & 804 & 302 & 301 & 200 & 2.65 & 6.94 & 0.08 & 0.04 & 4078.3 \\
Diaper Z & 7.12 & 2.40 & 619 & 271 & 278 & 68.3 & 2.68 & 5.97 & 0.10 & 0.07 & 4640.2 \\
Imp pant & 18.20 & 0.52 & 772 & - & - & - & $-*$ & - & $-{ }^{*}$ & $-{ }^{*}$ & 1807.4 \\
\hline
\end{tabular}

*: values outside of the range of the methods used (too large). Per pant: permeable pant, Imp pant: impermeable pant, SAP: a part with super absorbent polymer, Side $^{2}$ : two layers of non woven part, Side ${ }^{1}$ : one layer of non woven part, AAV: area weighted average value 
Table 2 Comparison of mean differences of VENT between rest and walking. Unit:(l/min)

\begin{tabular}{|c|c|c|c|c|c|c|c|}
\hline sample & motion & $\mathrm{N}$ & $\begin{array}{l}\text { Mean } \\
\text { ventilation }\end{array}$ & SD & t value & $d f$ & $p$ value \\
\hline \multirow{2}{*}{ all } & rest & 60 & 1.01 & 0.06 & \multirow{2}{*}{-2.03} & \multirow{2}{*}{118} & \multirow{2}{*}{0.045} \\
\hline & walk & 60 & 1.20 & 0.07 & & & \\
\hline \multirow{2}{*}{ Per pant } & Rest & 12 & 1.49 & 0.16 & \multirow{2}{*}{-3.58} & \multirow{2}{*}{22} & \multirow{2}{*}{0.002} \\
\hline & walk & 12 & 1.70 & 0.12 & & & \\
\hline \multirow{2}{*}{ Diaper X } & rest & 12 & 1.12 & 0.11 & \multirow{2}{*}{-4.12} & \multirow{2}{*}{22} & \multirow{2}{*}{0.0001} \\
\hline & walk & 12 & 1.32 & 0.13 & & & \\
\hline \multirow{2}{*}{ Diaper Y } & rest & 12 & 1.03 & 0.07 & \multirow{2}{*}{-6.58} & \multirow{2}{*}{22} & \multirow{2}{*}{0.0001} \\
\hline & walk & 12 & 1.28 & 0.11 & & & \\
\hline \multirow{2}{*}{ Diaper Z } & rest & 12 & 1.28 & 0.26 & \multirow{2}{*}{-2.42} & \multirow{2}{*}{15.4} & \multirow{2}{*}{0.029} \\
\hline & walk & 12 & 1.47 & 0.12 & & & \\
\hline \multirow{2}{*}{ Imp pant } & rest & 12 & 0.14 & 0.016 & \multirow{2}{*}{-8.97} & \multirow{2}{*}{17.3} & \multirow{2}{*}{0.0001} \\
\hline & walk & 12 & 0.23 & 0.029 & & & \\
\hline
\end{tabular}

$\mathrm{SD}=$ standard deviation, $\mathrm{df}=$ degrees of freedom 
Table 3 Comparison of mean differences for the different diaper designs and significance of the walking effect (post hoc test).

In case of Rest

Unit:(I/min)

\begin{tabular}{|c|c|c|c|c|}
\hline & Permeable pant & Diaper X & Diaper Y & Diaper Z \\
\hline Diaper X & $0.37\left(^{* \star}\right)$ & - & & \\
\hline Diaper Y & $0.46\left(^{* \star}\right)$ & $0.07(\mathrm{~ns})$ & - & \\
\hline Diaper Z & $0.22\left(^{* *}\right)$ & $-0.16(n s)$ & $-0.24\left(^{* *}\right)$ & - \\
\hline Impermeable pant & $1.35\left(^{* \star}\right)$ & $0.98\left(^{* \star}\right)$ & $0.89\left(^{* \star}\right)$ & $1.14\left({ }^{* \star}\right)$ \\
\hline
\end{tabular}

In case of Movement

Unit:(I/min)

\begin{tabular}{l|l|l|l|l}
\hline & Permeable pant & Diaper X & Diaper $Y$ & Diaper Z \\
\hline Diaper X & $\left.0.38^{* *}\right)$ & - & & \\
\hline Diaper $Y$ & $0.42\left(^{* *}\right)$ & $0.04(\mathrm{~ns})$ & - & \\
\hline Diaper Z & $\left.0.23^{* *}\right)$ & $\left.-0.16^{*}\right)$ & $-0.20\left(^{* *}\right)$ & - \\
\hline Impermeable pant & $\left.1.47^{* *}\right)$ & $1.09\left(^{* *}\right)$ & $1.05\left(^{* *}\right)$ & $1.25\left(^{* *}\right)$ \\
\hline
\end{tabular}

Values: differences of mean, ${ }^{* *}: p<0.001,{ }^{*}: p<0.05 ;$ ns : not significant. 
Table 4 Post hoc comparison of the local ventilation values for the 4 studied locations.

Unit:(I/min)

\begin{tabular}{cccc}
\hline & L1 & L2 & L3 \\
\hline L2 & $-0.89\left({ }^{* * *}\right)$ & - & \\
\hline L3 & $-0.02(\mathrm{~ns})$ & $0.87\left(^{* * *}\right)$ & - \\
\hline L4 & $-0.16\left({ }^{* * *}\right)$ & $\left.0.73^{* * *}\right)$ & $-0.14\left({ }^{* * *}\right)$ \\
\hline
\end{tabular}

Values: differences of mean, ${ }^{* * *}: p<0.001$, ns:not significant 
Table 5 Post hoc analysis of the differences in ventilation between the different diaper designs for the location L2 as defined in fig. 3. Unit:( $/ / \mathrm{min})$

\begin{tabular}{lllll}
\hline & per pant & diaper $X$ & Diaper $Y$ & Diaper Z \\
\hline diaper $X$ & $-0.67\left(^{\star *}\right)$ & - & & \\
\hline diaper $Y$ & $-0.87\left(^{*}\right)$ & $-0.20(\mathrm{~ns})$ & - & - \\
\hline diaper Z & $-0.74\left(^{\star *}\right)$ & $-0.08(\mathrm{~ns})$ & $0.12(\mathrm{~ns})$ & $1.43\left(^{* * *}\right)$ \\
\hline imp pant & $0.69\left(^{* * *}\right)$ & $1.36\left(^{* * *}\right)$ & $1.55\left(^{* * *}\right)$ &
\end{tabular}

Values: differences of mean, ${ }^{* * *}: p<0.001,{ }^{* *}: p<0.01 ; ;^{*}: p<0.05$, ns: not significant level 
Table 6 Post hoc comparison of the local ventilation values for the 4 studied locations in case of diaper $\mathrm{X}$.

Unit:(I/min)

\begin{tabular}{lllll}
\hline & main & L1 & L2 & L3 \\
\hline L1 & $0.97\left(^{(* *}\right)$ & - & & \\
\hline L2 & $-0.23(\mathrm{~ns})$ & $-1.20\left(^{* * *}\right)$ & - & \\
\hline L3 & $0.96\left(^{* * *}\right)$ & $-0.018(\mathrm{~ns})$ & $1.18\left(^{* * *}\right)$ & - \\
\hline L4 & $0.78\left(^{(* *}\right)$ & $-0.19\left(^{* * *}\right)$ & $1.01\left(^{* * *}\right)$ & $-0.17\left(^{* * *}\right)$ \\
\hline
\end{tabular}

Values: differences of mean, ${ }^{\star *}: p<0.001$, ns: not significant. 
Table 7 Post hoc comparison among rest and two speeds of motion on local ventilation values for the 4 studied locations in case of impermeable pant.

Unit:(I/min)

\begin{tabular}{|c|c|c|c|}
\hline & & rest & Walk slow \\
\hline \multirow{2}{*}{ all } & Walk slow & $-0.023(\mathrm{~ns})$ & - \\
\hline & Walk normal & $-0.032\left(^{\star}\right)$ & $-0.008(n s)$ \\
\hline \multirow{2}{*}{ L1 } & Walk slow & $-0.011\left(^{*}\right)$ & - \\
\hline & Walk normal & $-0.010(n s)$ & $0.001(\mathrm{~ns})$ \\
\hline \multirow{2}{*}{ L2 } & Walk slow & $-0.011\left(^{*}\right)$ & - \\
\hline & Walk normal & $-0.010(n s)$ & $0.001(\mathrm{~ns})$ \\
\hline \multirow{2}{*}{ L3 } & Walk slow & $-0.006(n s)$ & - \\
\hline & Walk normal & $-0.008(n s)$ & -0.002 (ns) \\
\hline \multirow{2}{*}{ L4 } & Walk slow & $-0.006(n s)$ & - \\
\hline & Walk normal & $-0.008(n s)$ & $0.002(\mathrm{~ns})$ \\
\hline
\end{tabular}

Values: differences of mean, ${ }^{*}: p<0.05$, ns: not significant. 


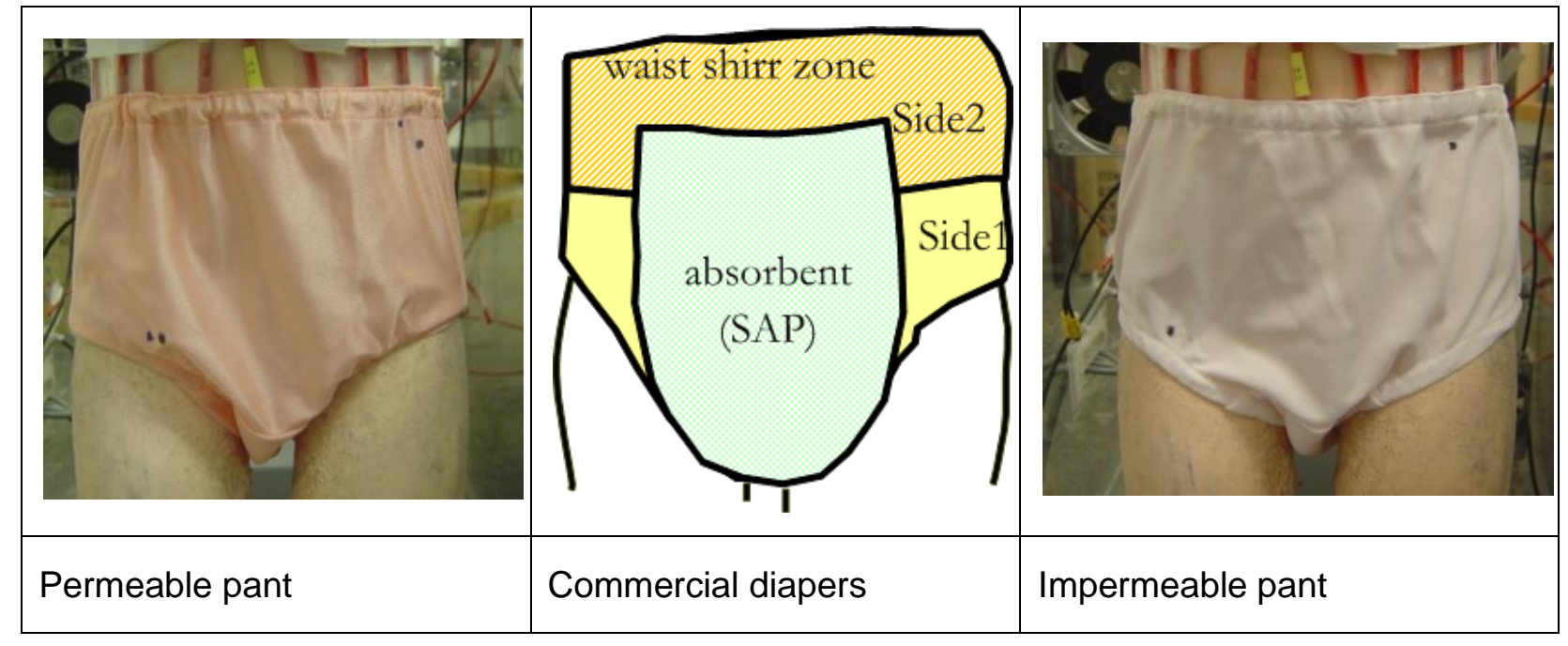

Fig.1 Photograph of two pants and schematic diagram of commercial diapers. 


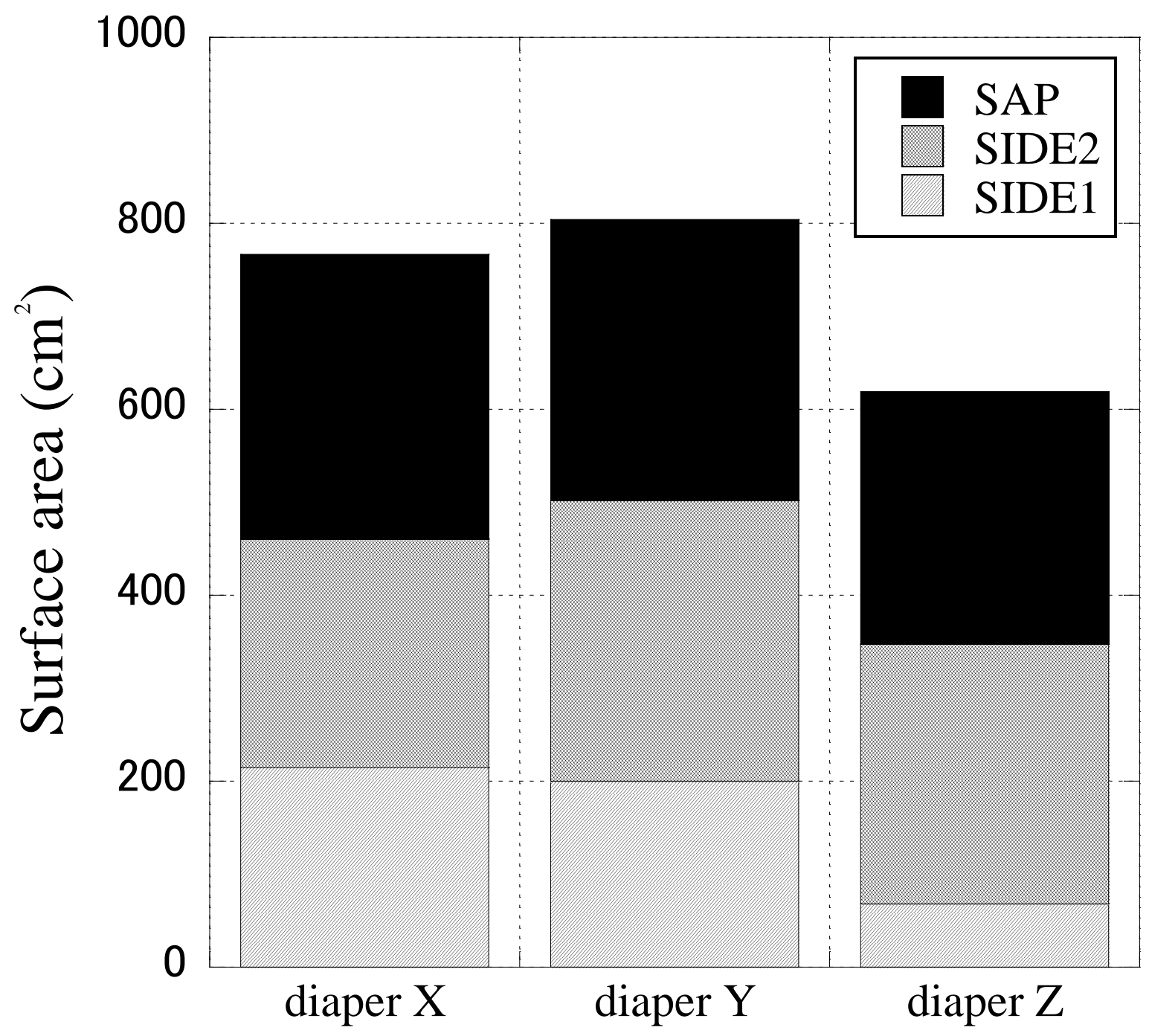

Fig.2 Surface cover area of three commercial diapers. 


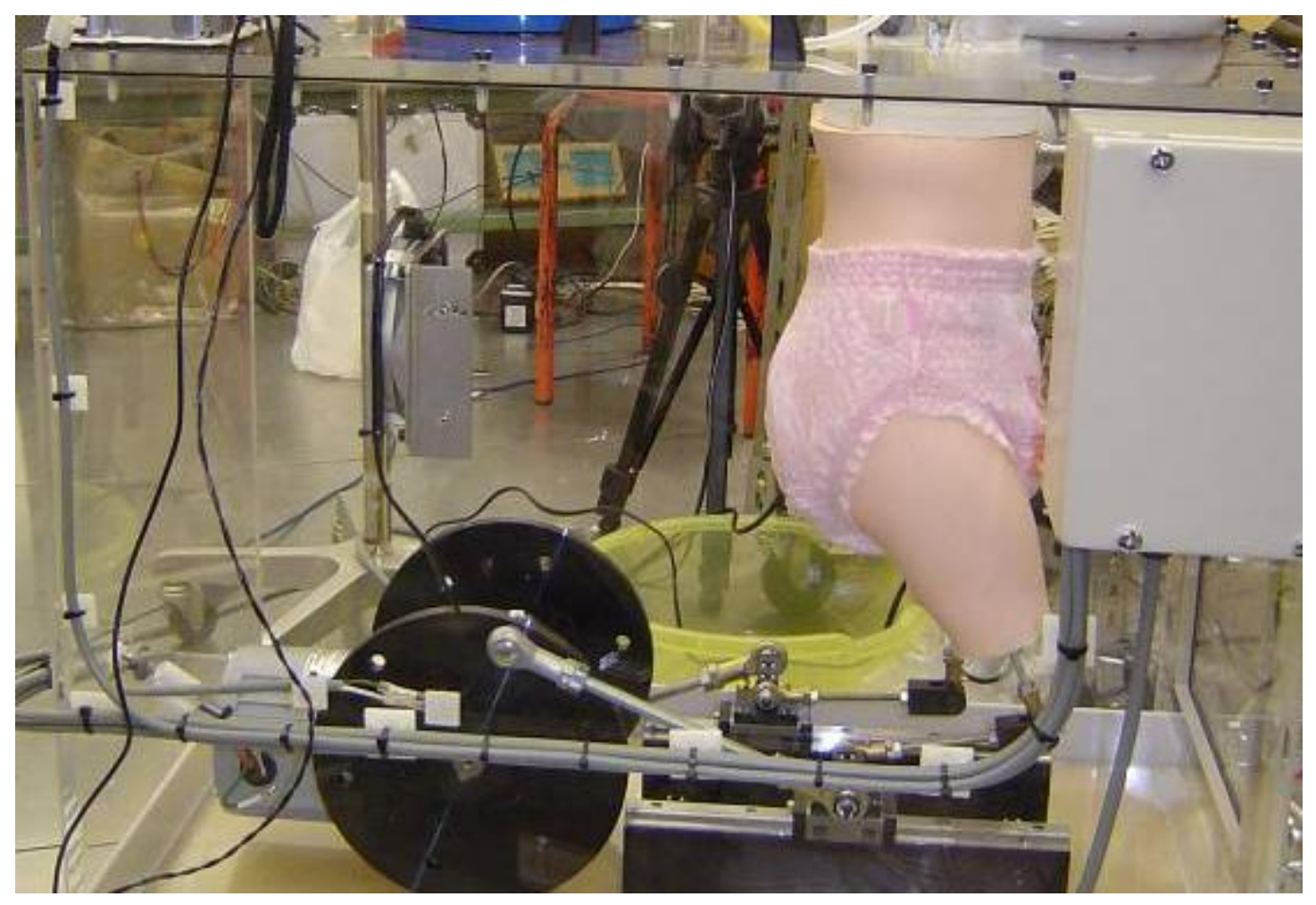

Fig.3 Photograph of the ventilation apparatus showing the manikin model and the movement mechanism inside the Perspex box. The box walls facing the front and back of the manikin are open to the environment to avoid $\mathrm{CO}_{2}$ buildup. 


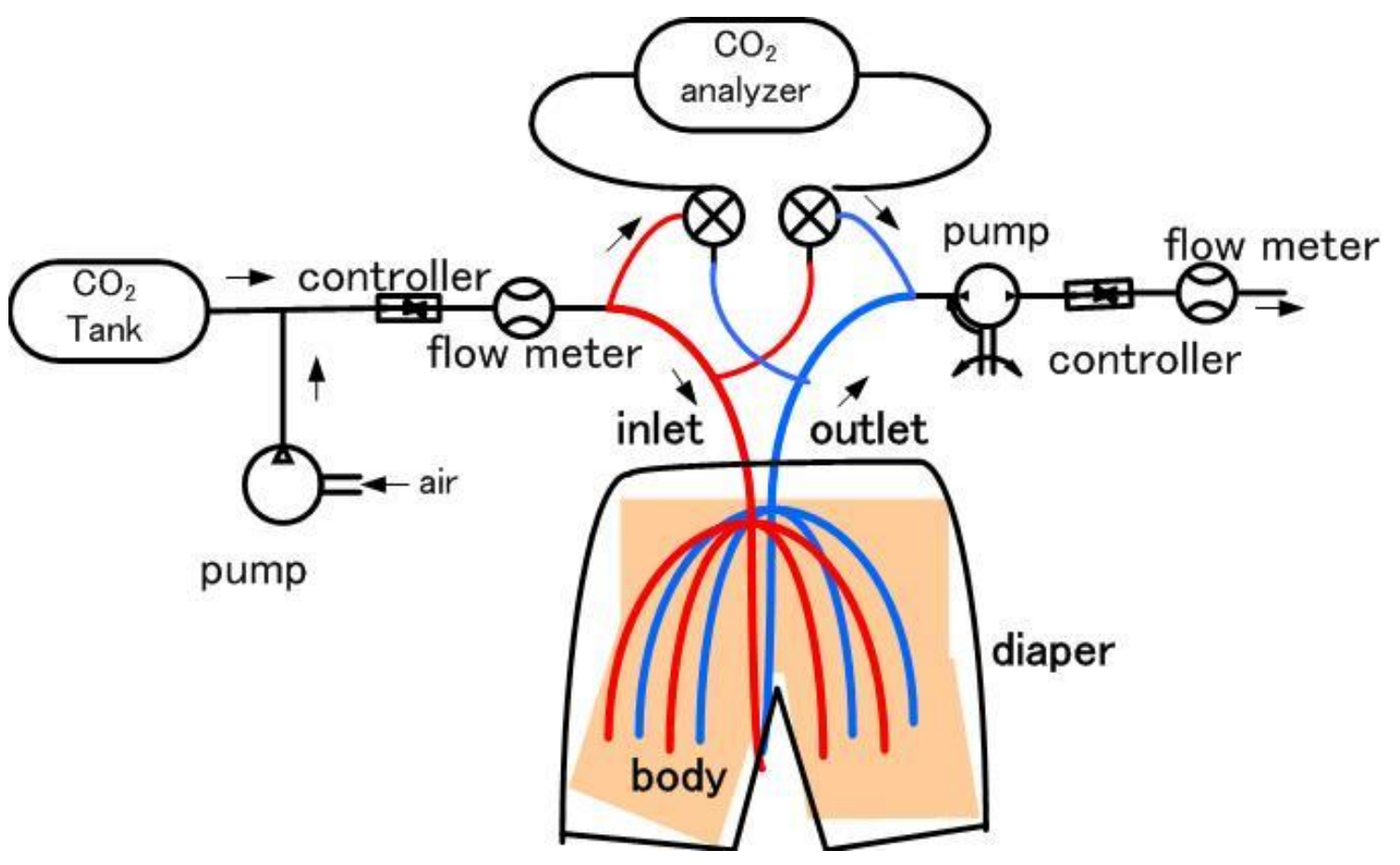

Fig. 4 Schematic diagram of ventilation system. 


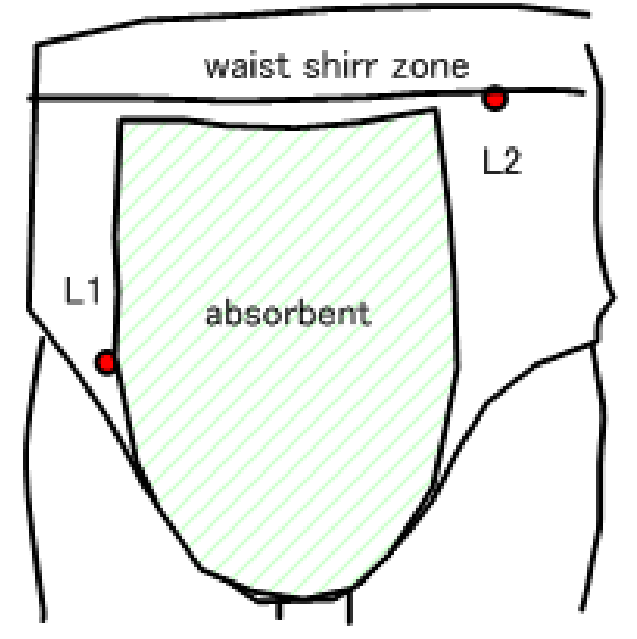

front viewback view

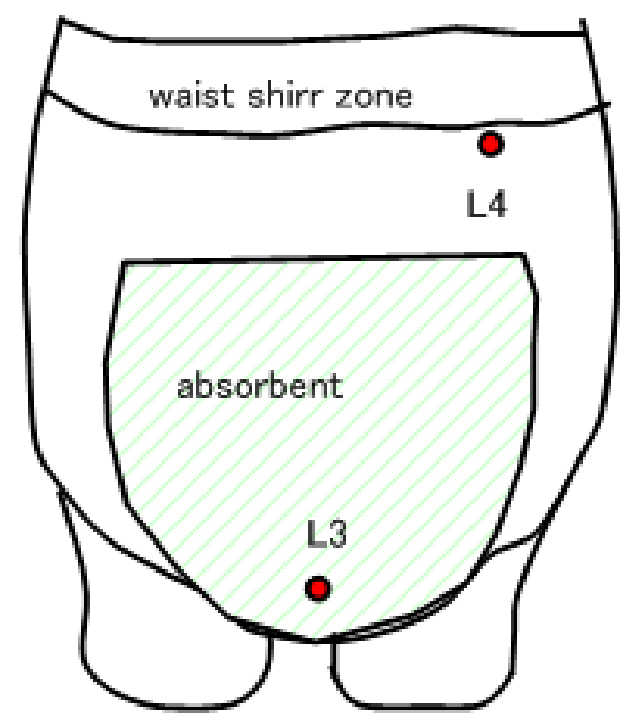

back view

Fig.5 Local measurement sites. 


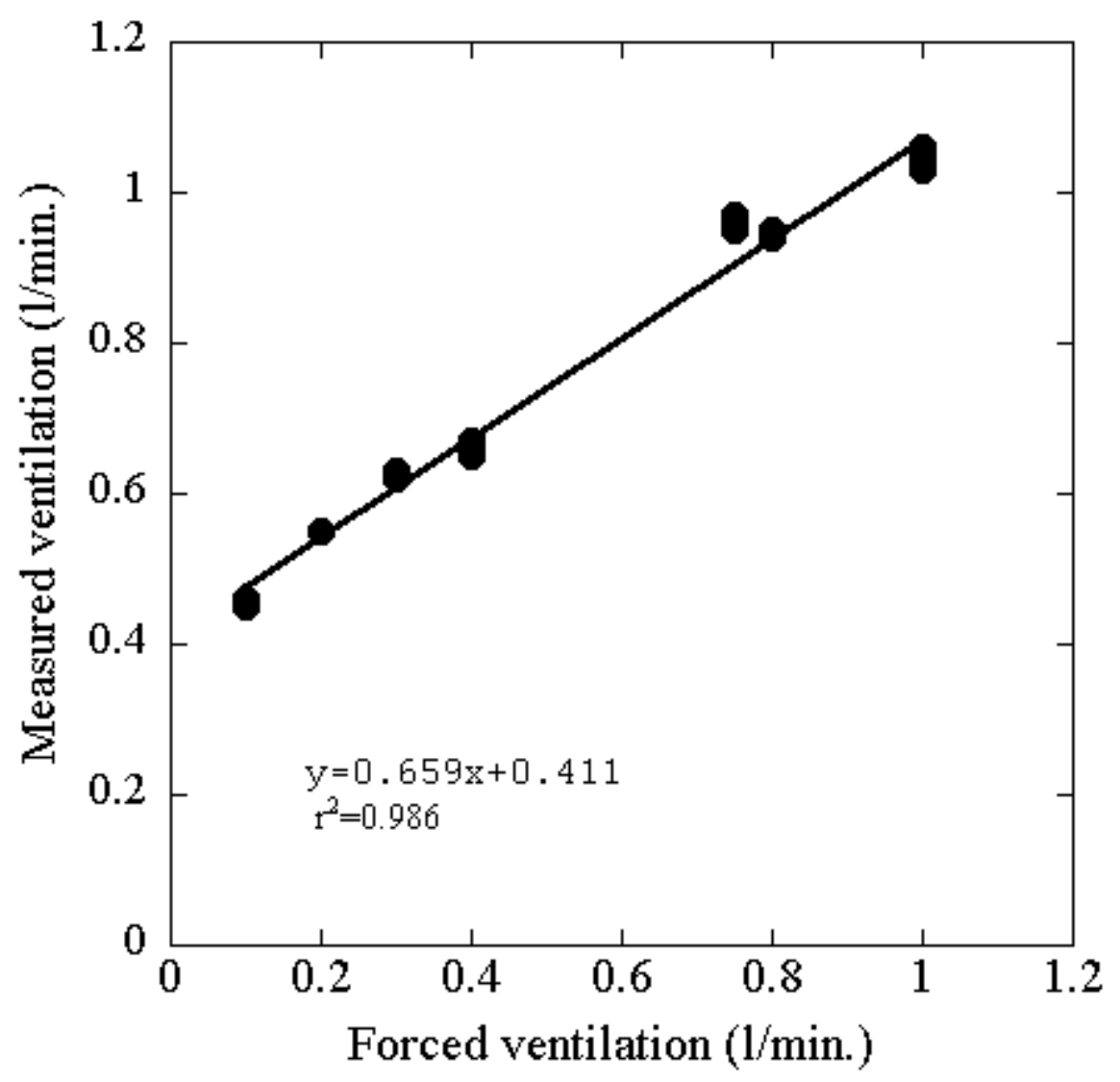

Fig.6 Validation of ventilation data by comparison with forced convection values. 


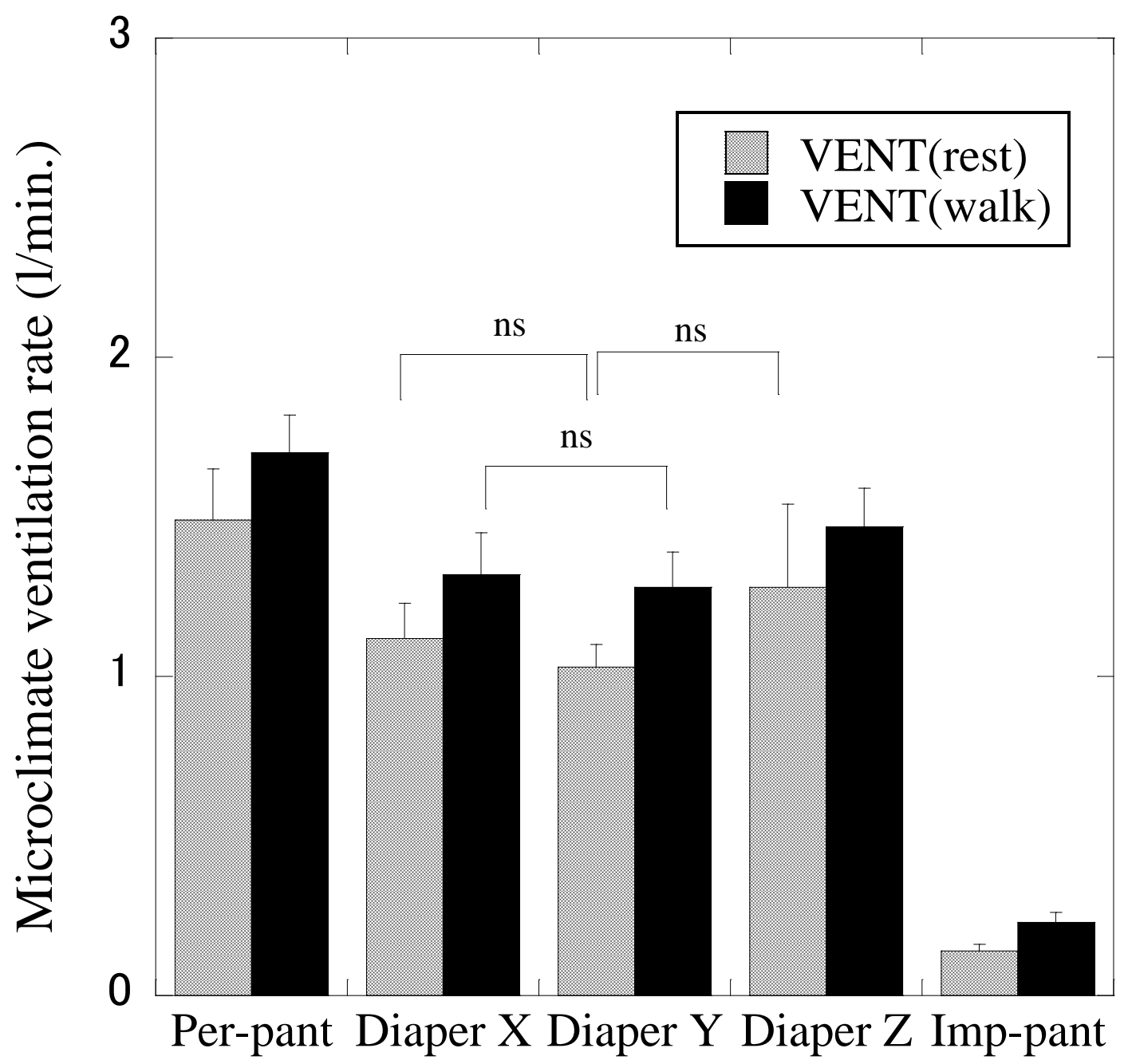

Fig.7 Overall microclimate ventilation rate of diapers and pants. All comparisons except those indicated are statistically significant. ns: not significant. Per-pant=permeable pant; Imp pant=Impermeable pant diaper. 


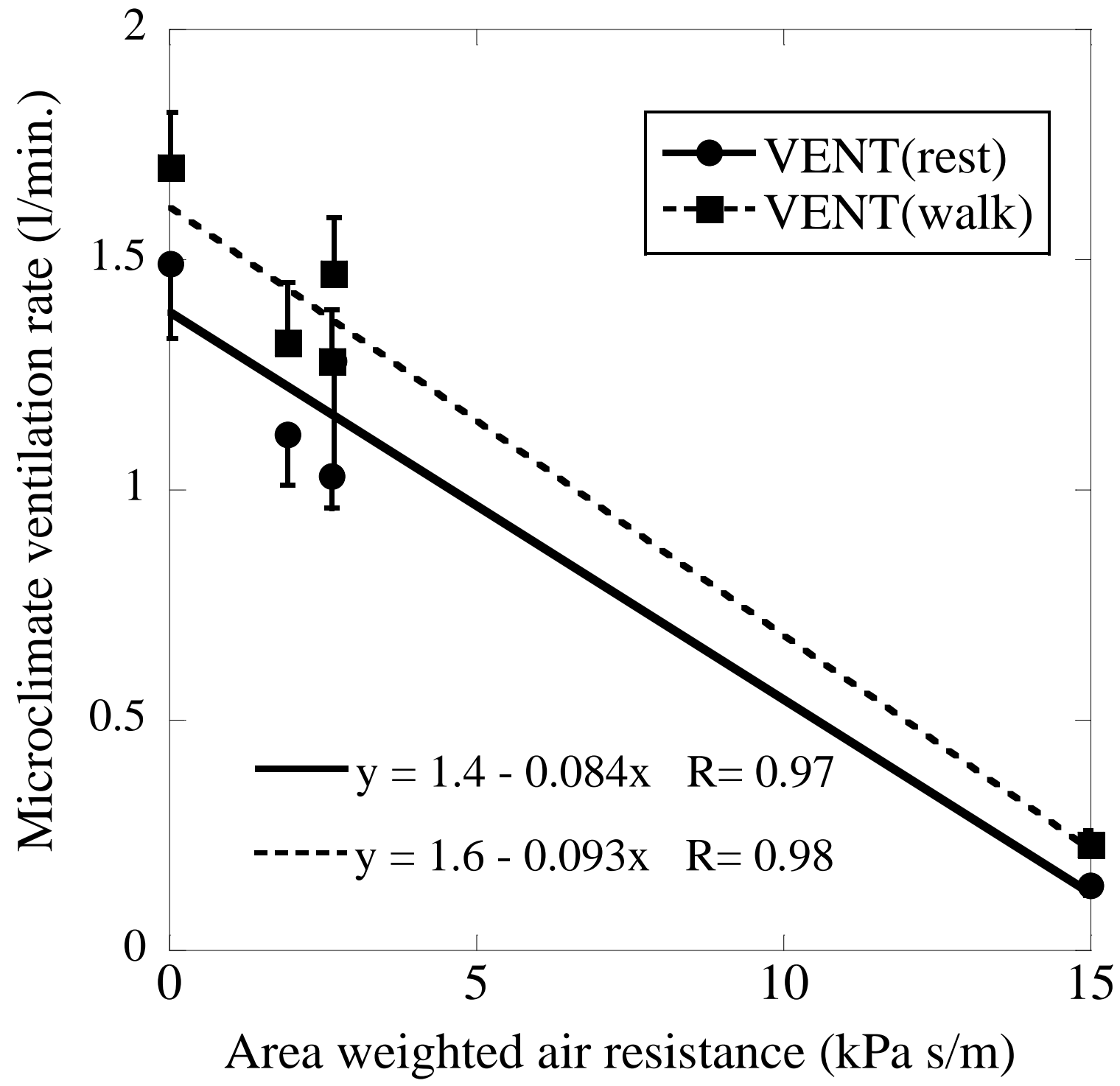

Fig. 8 Relation between area weighted air resistance and the microclimate ventilation rate of diapers and pants. For the impermeable pant, as its air resistance could not be measured, an estimate was used as input. 


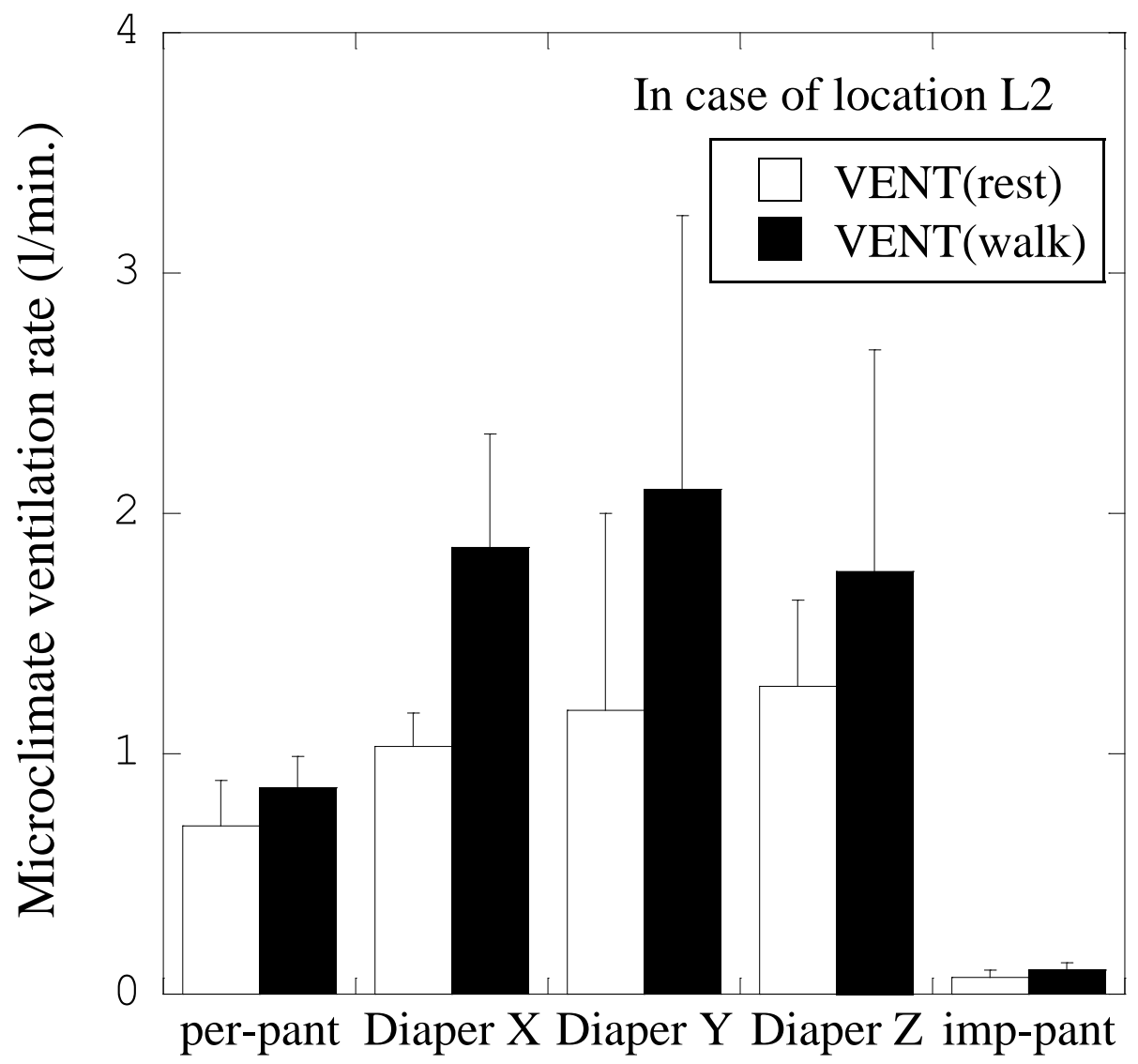

Fig.9 Local microclimate ventilation rate of diapers and pants for location L2 in relation to diaper type and movement. Values are mean \pm SE. For significance levels see Table 5 . 


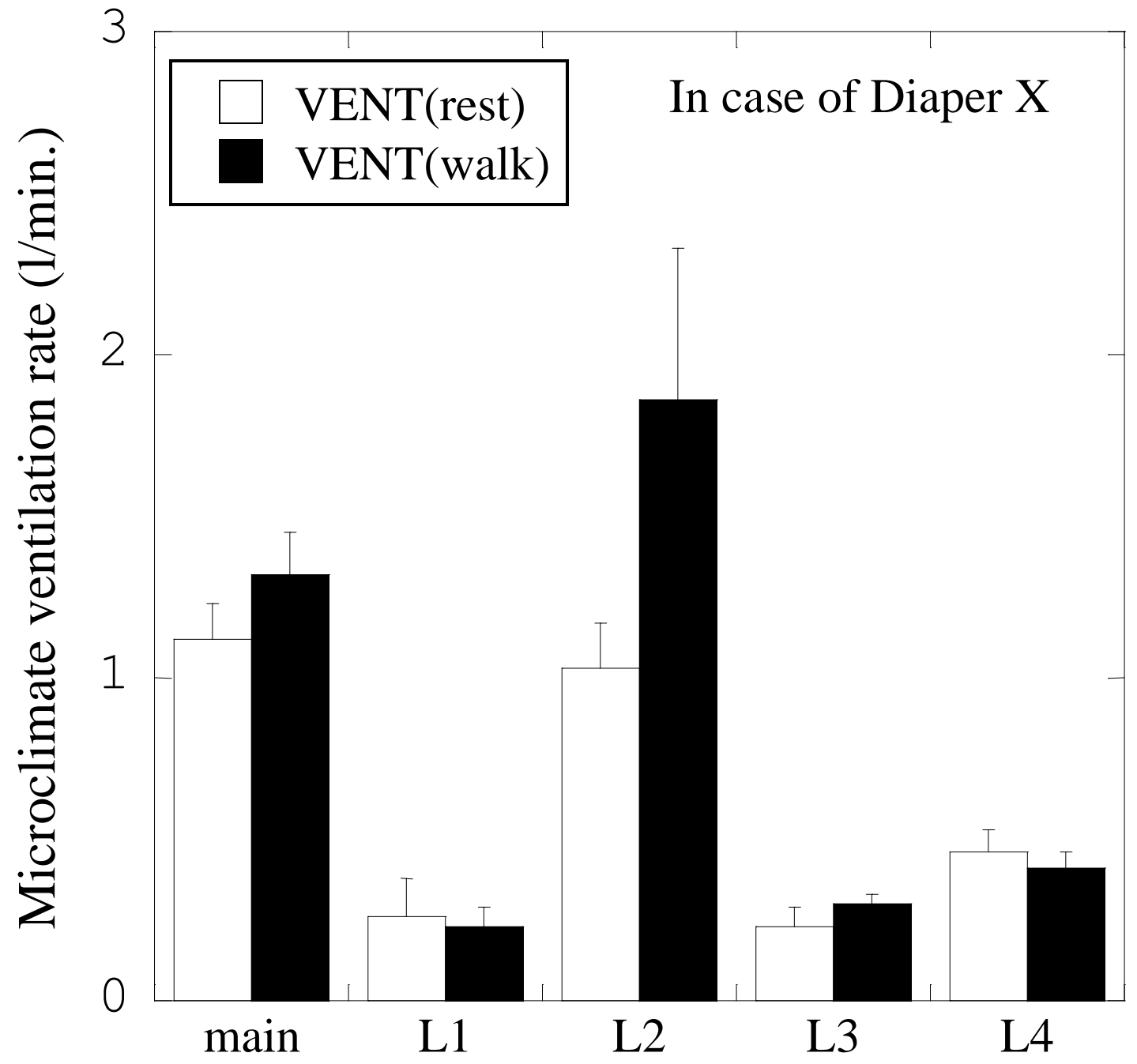

Fig. 10 Local distribution of ventilation rate for diaper X. All comparisons except those indicated are statistically significant. ns: not significant. For significance levels see Table 6 . 


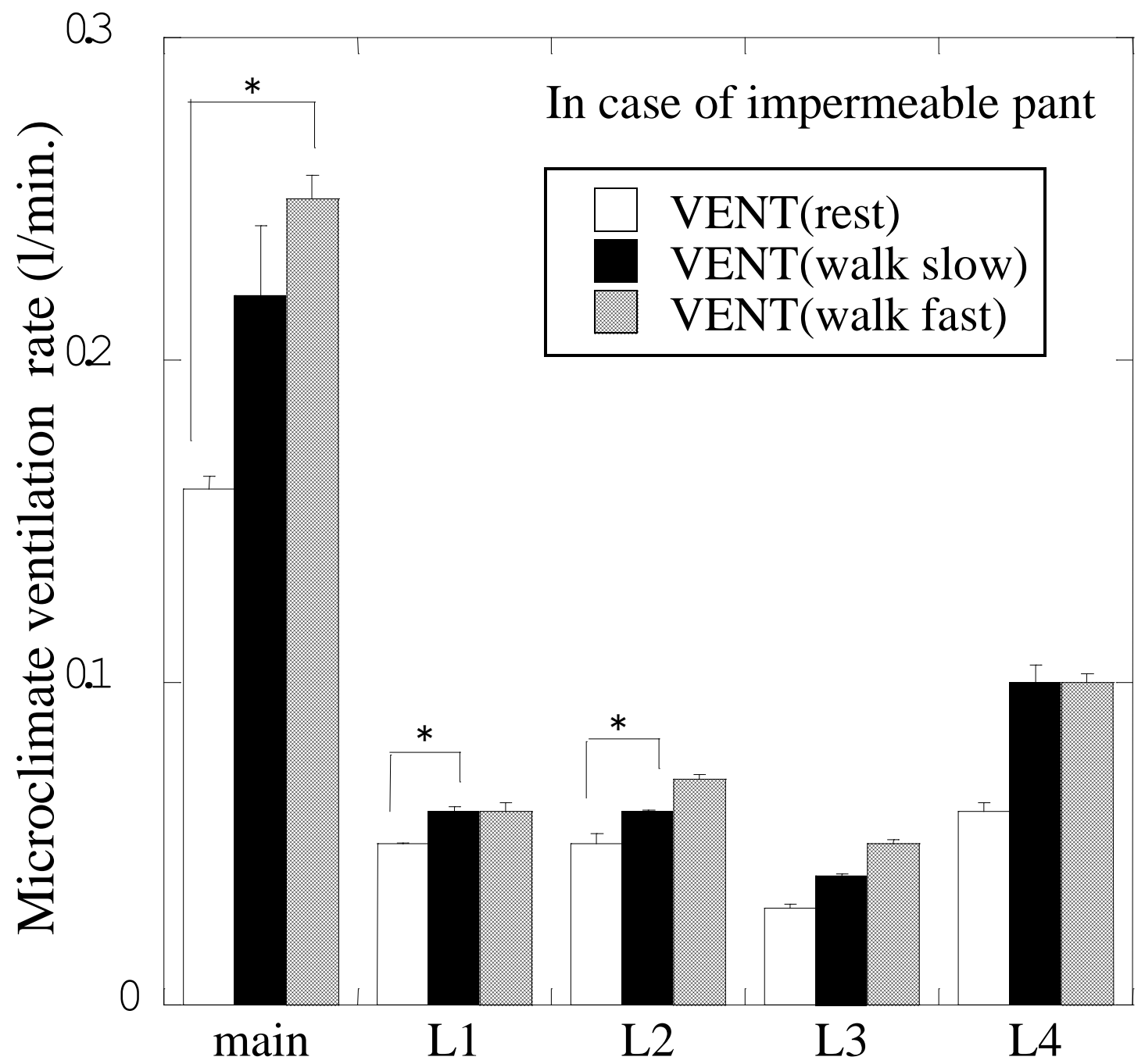

Fig.11 The effect of walking speed on local microclimate ventilation rate for the impermeable pant. Values are mean \pm SE. Differences between rest and walk normal are significantly different only in main. Differences between rest and walk slow are significantly different only at L1 and L2. For significance levels see Table 7. 

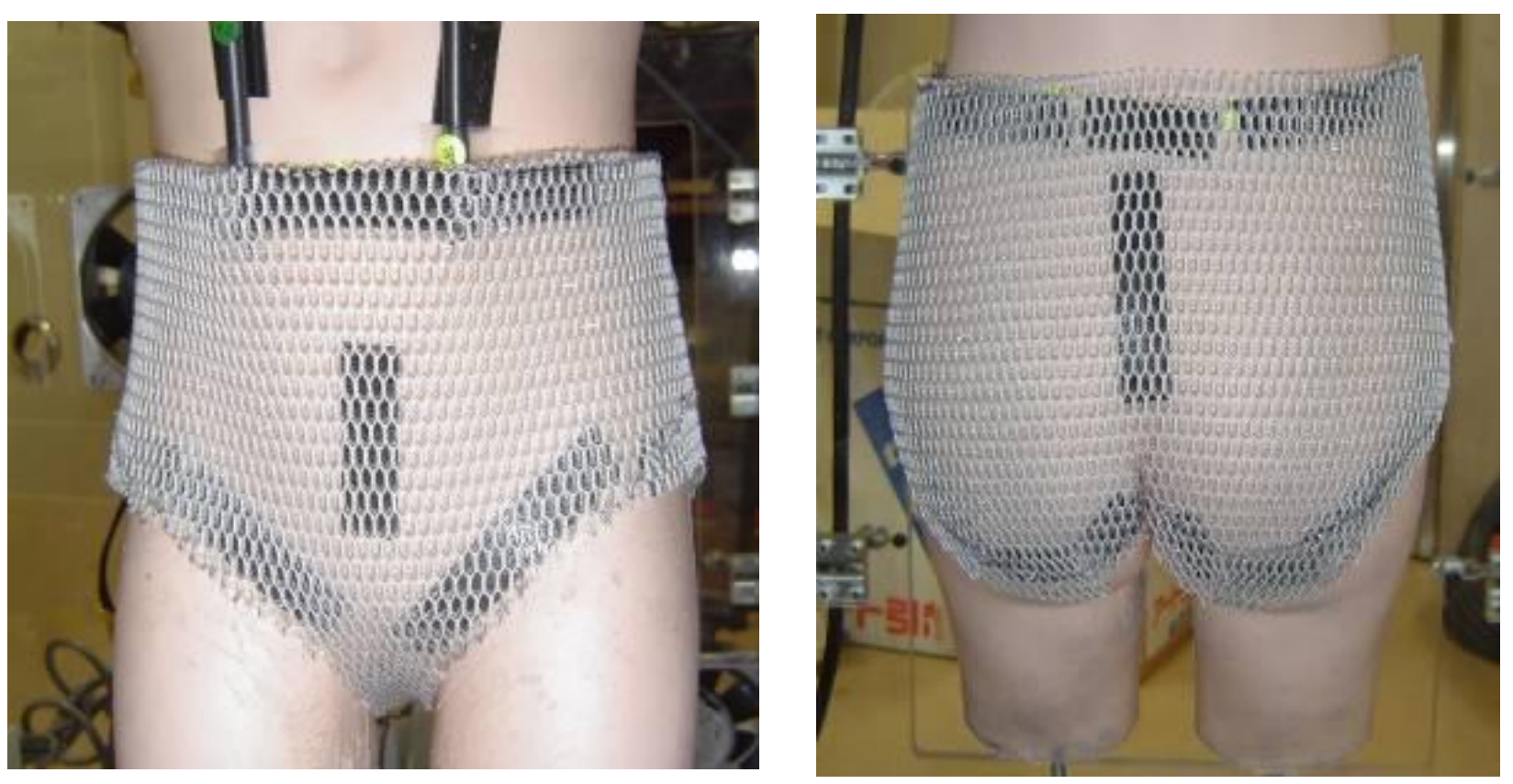

Fig.12 Mesh fabric placed underneath the diapers to stabilize the microclimate volume. 


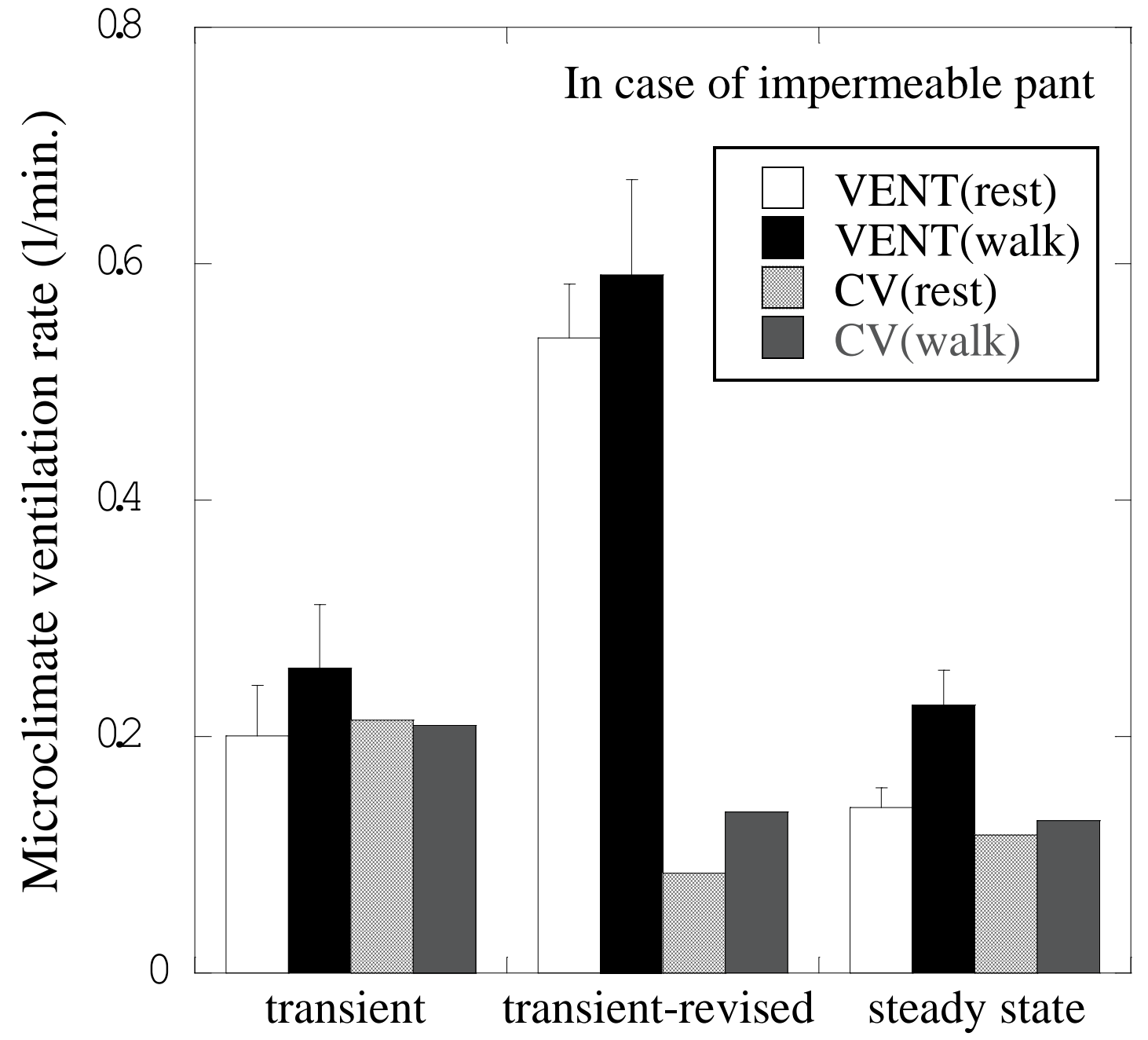

Fig.13 Comparison of the two tracer gas methods. Left: transient method; centre: modified transient method; right: steady state method. Ventilation for rest and walking $( \pm S E)$ and the coefficient of variation for these tests (expressed as fraction of the mean). 